\title{
Can We Really Prevent Suicide?
}

\author{
Maya Schwartz-Lifshitz • Gil Zalsman • Lucas Giner • \\ Maria A. Oquendo
}

Published online: 21 September 2012

(C) Springer Science+Business Media, LLC 2012
Keywords Suicide $\cdot$ Risk factors $\cdot$ Diagnostic risk factors Depressive disorders $\cdot$ Bipolar disorders $\cdot$ Anxiety disorders · Alcohol and other substance abuse $\cdot$ Schizophrenia . Aggression, impulsivity, and hostility · Hopelessness . Heredity $\cdot$ Childhood trauma $\cdot$ Past attempts $\cdot$ Prevention . Means restriction $\cdot$ Media coverage $\cdot$ Identification methods Diagnosis · Treatment $\cdot$ Psychotherapy $\cdot$ Pharmacotherapy Electroconvulsive therapy $\cdot$ Mood disorders $\cdot$ Psychiatry

\section{Introduction}

The World Health Organization (WHO) defines suicide as the act of killing oneself. The act must be deliberately initiated and performed by the person concerned in the full knowledge, or expectation, of its fatal outcome [1]. Suicide is among the top 20 leading causes of death globally for all ages and every year, nearly one million people die from suicide. Worldwide, suicide ranks among the three leading causes of death among those aged 15-44 years, and the second leading cause of death in the 10-24 years age group [2]. The global suicide rate is 16 suicides per 100,000 inhabitants: more specifically 18 suicides per 100,000 males and 11 suicides per 100,000 females [2]. Clinical studies have demonstrated that in most countries, suicide predominates in males, although there are important exceptions such as China. Of note, the suicide rate increases with age, although suicide rates among young people have been increasing to such an extent that they are now the group at highest risk in a third of countries, in both developed and developing countries. As well, there are marked differences in suicide rates between some ethnic groups and individual countries, and also within different regions of one country.

A suicide attempt is a self-inflicted, potentially injurious behavior with a nonfatal outcome for which there is evidence (either explicit or implicit) of intent to die [3, 4]. It is estimated that for every suicide, there are 50 suicide attempts, and thus 
attempts are a source of significant morbidity. Moreover, the Youth Risk Behavior Surveillance study suggests that as many as $7 \%$ of adolescents in the United States acknowledge having attempted suicide.

Identifying individuals at imminent risk for suicidal behavior is a major challenge for clinicians. In general, suicide is hard to predict because the prevalence of risk factors is high among the population, while suicide is rare. Indeed, only a minority of those with risk factors will commit suicide. Furthermore, some of the risk factors are not specific and of those who die by suicide, some are not in any risk group. Nonetheless, up to $90 \%$ of the people who commit suicide, and a similar rate of those who attempt suicide, suffer from a psychiatric disorder (affective illnesses, drugs/alcohol abuse, psychosis or personality disorders [5-8]). On the other hand, among psychiatric populations, suicidal behavior is not rare and the rate of attempts among psychiatric patients ranges between $15-50 \%$ [9].

Despite the challenges in identifying those at risk for suicidal behavior, opportunities for prevention do exist. In many cases, suicidal persons have been in contact with general practitioners in the month prior to their death [10-12], although, up to $80 \%$ of them were not treated for their psychiatric condition at that time of death [13-15]. This contact with the medical profession may afford an opportunity for intervention.

\section{Risk Factors}

\section{Diagnostic Risk Factors}

\section{Depressive Disorders}

More than half of all clinically depressed persons have suicidal ideation and Major Depression Disorder and Bipolar Disorders are the psychiatric disorders most often associated with suicide [16]. Some symptoms of depression have been identified as particularly important in risk for suicidal behavior: hopelessness, feelings of guilt, loss of interest, insomnia, and low self esteem [17•]. Effective prevention and treatment of mood disorders might reduce the number of suicide attempts, given that most depressed patients at the time of suicide attempt are inadequately treated [16]. Thus, treating suicidal depressed patients actively and intensively might offer an effective way of preventing suicidal behavior.

\section{Bipolar Disorders}

Suicidal ideation is highly prevalent in patients with bipolar disorders, and it is estimated that as many as half of those who have bipolar disorder attempt suicide at least once. The suicide rate among these patients is more than 20 times higher than that of the general population [5] and the risk of suicide is highest early in the course of Bipolar Disorder, particularly in the first year of the illness. The presence of depressive and dysphoric-irritable states in Bipolar Disorder is reported to be a risk factor for suicide [8]. Other work suggests that hopelessness predicts suicidal behavior during the depressive phase, and that severity of depression predicts suicide attempts during mixed episodes [17•]. Therefore, aggressive and effective management of depressive phases is essential, as depressive phases are high risk periods for suicidal behavior.

\section{Anxiety Disorders}

Anxiety disorders are associated with lifetime suicidal ideation and suicide attempts, especially in adolescents and in young adults [18]. Among anxiety disorders, Panic Disorder and Post Traumatic Stress Disorder (PTSD) have the strongest associations with suicidal behavior. However, whether anxiety disorders alone or whether presence of anxiety in the context of a mood disorder increases risk for suicidal behavior remains an open question. For example, a link between suicidality and panic/anxiety disorders has been reported $[19,20]$ at times, independently from the presence of comorbid depression, substance abuse and personality disorders [3]. However, Placidi et al. [21] found that comorbid panic disorders in patients with major depression did not increase the risk for lifetime suicide attempts. Moreover, non-attempters scored higher in the anxiety items in the Hamilton depression scale. It may be that anxiety symptoms, like fear of disability or death, serves as a protective factor for suicide. In terms of PTSD, a review by Panagioti et al. [22] found a relationship between PTSD and suicidal thoughts and behaviors, irrespective of the type of trauma experienced. In many PTSD studies, suicidality is associated with comorbid depression and substance abuse [17•]. Therefore, the increased proportion of suicide attempters among persons with a PTSD diagnosis may be due to the comorbid depression and not to PTSD itself. Given that anxiety is highly comorbid with other mental disorders, especially mood disorders and substance abuse, the role of severe anxiety as a marker of acute suicide risk requires further study.

\section{Alcohol and Other Substance Abuse}

Substance misuse disorders increase the risk of suicidal behaviors, alcohol being the most significant risk factor among the substances. Alcohol misuse and abuse predispose to impulsivity, aggression, depression, hopelessness, and other negative factors that increase the risk for suicidal behavior. Individuals who commit suicide and suffer from alcohol and other substance abuse disorders are often younger males, divorced or separated. They often suffer from recent adverse life events, 
and are likely to be intoxicated at the time of the suicide [23]. In terms of suicide attempts, the presence of alcohol misuse disorders is also a significant risk factor. Moreover, when comorbid with affective disorders, presence of alcohol misuse disorders increases risk of suicide attempts by more than two fold [24].

\section{Schizophrenia and Other Psychoses}

Suicide attempt is prevalent in patients with schizophrenia and other psychotic disorders [25] and occurs in as many as $23-31 \%$ of those afflicted depending on the global region. Meanwhile, the lifetime suicide risk for people with schizophrenia is estimated to be about $5 \%$ [26]. The risk factors for suicide in schizophrenia are past and present suicidal behavior, past depressive episodes, drug abuse or dependence and more frequent psychiatric admissions [27]. Of note, other risk factors, such as fear of mental disintegration, agitation or restlessness, and poor adherence to treatment, all increase risk for suicidal behavior and may be more specific to schizophrenia [28]. The great majority of suicides in schizophrenia occur in the active phase of the disorder, in the context of depressive symptoms [17•]. That suicides are most common early in the course of the illness suggests that prevention and treatment should focus on the early stages of disease.

\section{Personality Disorders}

Personality disorders have been shown to be related to suicidal and self-injurious behavior, both among the general and the psychiatric population [29]. Moreover, many suicide attempters meet criteria for a personality disorder [30, 31]. Although borderline personality disorder is the only personality disorder that lists suicidal behavior as a criterion, other personality disorders, such as antisocial and other Cluster B personality disorders [32] also increase risk of suicidal behavior. Personality disorders are often accompanied by impulsivity, aggression, alcohol and substance abuse, as well as major depressive episodes, all of which are known risk factors for suicide in their own right.

\section{Other Risk Factors}

\section{Aggression, Impulsivity, and Hostility}

Levels of impulsivity, hostility and aggression are higher in suicide attempters compared to non-attempters among people who suffer from major depression [33]. Among bipolar patients, past suicide attempters report more lifetime aggression than non-attempters [34]. Aggression is an important variable in the prediction of suicidal behavior as well [16]. Of note, although impulsivity contributes to the future risk of suicidal behavior [35], it appears to lower the lethality of the suicidal act, since it detrimentally affects one's planning ability. In support of this, older suicides are reported to have lower levels of impulsivity and aggression compared to young suicides.

\section{Hopelessness}

Hopelessness was found to be associated with future suicide attempts both in the short and long term [19, 36-38]. Furthermore, in mood disorders, it predicts suicidal behavior as part of a pessimism factor, which also includes measures of subjective depression, suicidal ideation and reasons for living [37]. Whether hopelessness as a trait rather than a symptom of depression is of import remains an open question.

\section{Heredity}

Suicidal behavior is highly familial $[3,39,40]$ and a family history of suicidal behavior is associated with suicide attempts and suicide all through the life cycle and across psychiatric diagnoses [41]. This transmission is independent of the transmission of psychiatric disorders [42, 43]. Instead, the familiality of suicidal behavior appears to be mediated by the transmission of a tendency to impulsive aggression, traits that leads the patient to a higher tendency to act upon suicidal thoughts $[44,45]$.

\section{Childhood Trauma}

Childhood trauma is also a risk factor for suicide attempt. Moreover, the amount of trauma experienced by the child, correlates with younger age at the first suicide attempt and an increased number of suicide attempts [46].

\section{Past Attempts and Ideation}

A suicide attempt in the past is a major risk factor for suicide $[3,16]$ as well as future suicide attempt, especially among people suffering from affective disorders [46-52]. Repeated suicide attempts increase the risk of future suicidal behavior, as was demonstrated by Leon et al. [53]. Oquendo et al. [54] found a $50 \%$ increase in the risk of future suicidal behavior for each previous attempt made by the individual. The evidence for suicidal ideation by itself as a risk factor for suicide acts is more nuanced. In a prospective study [37], suicidal ideation alone did not predict future suicide attempts or completion. In contrast, other studies have identified suicidal ideation as a precursor of attempted and completed suicide among patients with mood disorders [55-58] and as correlated with greater risk of future suicide attempts (as part of a pessimism factor) among bipolar 
patients presenting with a major depressive episode [59]. Not surprisingly, suicide attempters also are more likely to endorse suicidal ideation during subsequent acute phases or hospitalizations $[34,60]$. Therefore, it is reasonable to view suicide ideation as a risk factor for suicide, either as an independent risk factor, or as part of a factor integrating measures of subjective depression, reasons for living, and hopelessness [16].

\section{Preventive Measures}

Since a variety of factors are involved in the suicidal act, multimodal approaches covering multiple levels of intervention and activities will be essential to any preventive strategy. Thus far, prevention strategies found to be effective in suicide prevention include means restriction, responsible media coverage and general public education, as well identification methods such as screening, gatekeeper training, and primary care physician education.

\section{Means Restriction}

Suicide attempts using highly lethal means, such as firearms in US men, or pesticides in rural China, India, and Sri Lanka, result in high rates of death [10]. The most frequent means of suicide in Europe is hanging [61] and in North America, firearms [62]. Suicide methods are necessarily influenced by their accessibility. In many countries, restriction of access to common means of suicide has led to lower overall suicide rates [63]. For example, increasing firearm control in the US and Canada [64-66], detoxification of domestic and motor vehicle gas [67, 68], restrictions on use of toxic pesticides in rural areas [10], and physical barriers at jumping sites $[69,70]$ are reported to be of utility in reducing suicides. In addition, reducing access to ligature and ligature points in prisons and hospitals has reduced instances of hanging [71] while introducing safer antidepressant, selling smaller packages of analgesics or individually wrapped analgesics, and restricting of the sale of barbiturates has reduced suicides by overdose [72]. Thus, public policy to reduce access to means for suicide has an important role in prevention.

\section{Responsible Media Coverage}

Responsible media coverage is key to suicide prevention by providing the public information on mental disorders and their treatment, and ways of identifying persons at risk. Glorification and dramatization of a suicidal act can be followed by a series of suicides, especially among adolescents ("contagion"), thus it is important to stress that the person who lost his life to suicide is ill and not in any way a hero. Programs to educate the media about coverage of suicides are available through foundations (American Foundation for Suicide Prevention) and emphasize the importance of reporting suicide as a public health issue, in a non-sensational way. Media coverage should emphasize the treatable causes of suicide, such as substance abuse and mental disorders. Discussing the available treatment options for these problems and the types of healthcare providers who can treat them may encourage help seeking behavior by those contemplating suicide. As well, because many individuals considering suicide exhibit warning signs, educating the public about such signs can help relatives identify and respond quickly and efficiently to the person in need. In addition, it is essential that media coverage not link suicide only to external events, like divorce, a recent job loss or school failure, dramatic as they may be. Instead, emphasizing the frequency of psychiatric conditions among those who die by suicide and providing education about possible interventions can be helpful to communities exposed to highly visible suicides. Of note, media reports covering specific suicide methods were found to increase suicidal behaviors in the community in some studies [73, 74]. Therefore, it is advisable to avoid inclusion of specific details such as the location or method of death in news reports.

\section{Identification Methods}

Before suicidal behavior can be prevented, those at risk need to be identified. Since not all potential suicide attempters are in close contact with a mental health professional, those around them (e.g., friends, family, school staff, military commanders and primary care givers) should be equipped with tools to properly identify risk and make a timely referral.

\section{General Public Education}

Public education campaigns are aimed mostly at improving suicide risk recognition and help-seeking behavior and reducing the stigma of mental illness [75••]. Some campaigns address suicidal behavior directly, as was done in the United States Air Force suicide prevention program [76], while others target depressive disorders [77-79]. However, Mann et al. [10] found no detectable effects of public awareness campaigns, neither on reducing the rate of suicidal acts, or on increasing treatment seeking or antidepressant use. Further, a review by Dumensil and Verger [80 ${ }^{\circ}$ examined 15 public education campaigns in eight countries and found that these programs improved the general public's knowledge of suicide and depression and contributed at least moderately to better social acceptance of people with depression and other mental illnesses. Unfortunately, no study clearly demonstrates increased care seeking or decreased suicidal behavior after such campaigns. However, it still 
may be the case that awareness campaigns have an effect when combined with other measures in a multilevel and multifaceted intervention program [76, 81]. This was demonstrated in the Nuremberg Alliance against Depression (NAD), a two year intervention program that included four levels: (1) Training of general practitioners and support through different methods; (2) A public relations campaign informing about depression, (3) Cooperation with community facilitators (teachers, priests, local media, etc.), and (4) Support for selfhelp activities as well as for high-risk groups. The program was found to be effective in lowering the rate of suicidal acts by approximately $20 \%$ (suicide attempts and completed suicide) [81]. The program demonstrated the additive and synergistic effect of combining all four intervention levels simultaneously. The European Alliance against Depression (EAAD), an EUfunded network of partners from 17 countries adopted this multifaceted intervention approach, and is currently conducting a test in Hungary, Portugal, Germany and Ireland. Results of this initiative have yet to be released.

\section{Primary Care Physicians Training}

On average, $77 \%$ of the people who commit suicide were in contact with a primary care physician in the year before their death, and about $45 \%$ came in contact with a primary care provider in the month prior to their death [11]. However, under-recognition and under-treatment of psychiatric disorders in primary care setting presents a challenge for identifying those at risk and while mental disorders are present in most cases of suicide, most suicides are untreated at the time of death [13]. Fortunately, education of primary care physicians in recognition and treatment of depression may be an efficient means for lowering suicide rates $[10,63,82]$. Indeed, studies that examined programs for primary care physician training found a rise in the antidepressant prescription rates and a decline in the suicide rate after the program $[81,83]$.

\section{Gatekeeper Training}

Gatekeepers are figures with the potential to influence the suicidal person on a temporary or ongoing basis (e.g., family members, friends, authority figures- a parent, teacher or a military commander, educators, social workers, nursing home staff and volunteers) and can serve as a support resource. The training of gatekeepers focuses on recognizing suicidal thinking and behavior and helping people at risk to access appropriate services [10]. The key elements of the training include: learning about depression and suicide, training in practical elements (e.g., how to talk about suicide, detect suicide risk, handle an acute suicidal crisis etc.), instruction on what to do if treatment needs are encountered, and strategies for recognizing populations vulnerable to suicide $[75 \bullet \cdot$. Success of gatekeeper training in lowering suicide rates has been reported in military and school programs [76, 84]. In a group-based randomized trial conducted by Wyman et al. [85], Question, Persuade, Refer (QPR) training of a random sample of school staff increased their knowledge of youth risk factors for suicide. The program also increased the staff's commitment to assisting students in receiving help before engaging in potentially lethal self-harm behaviors. The gatekeeper training, however, did not overcome the students' reluctance to seek assistance from adults, underscoring the need to improve the communication between school staff and difficult-to-reach students.

\section{Screening}

Screening aims to identify at-risk individuals and direct them to treatment [10]. The Columbia Suicide Screen ${ }^{\circledR}$ (CSS) questionnaire is a brief, self-administered set of questions intended to identify high school students at risk of suicide. In a study that examined the efficiency of the CSS in identifying high school students at risk of suicide [86], the algorithm that gave both the highest specificity and the best balance between sensitivity and specificity ( 0.75 and 0.83 , respectively) screened for suicidal ideation or previous attempt and self reported unhappiness, withdrawal, or irritability and anxiety. A review of studies of depression screening in adults in primary health care settings performed for the US Preventive Services Task Force [87] found higher detection and diagnosis rates of depression through the use of screening tools. It was also found that brief questionnaires, such as the PHQ-2 which ask two questions: (1) "Over the past 2 weeks, have you felt down, depressed or hopeless?" and (2) "Over the past 2 weeks, have you felt little interest or pleasure in doing things?" appeared to perform as well as lengthier questionnaires (e.g., the Zung Self-Depression Scale and the Beck Depression Inventory). Indeed, screening was associated with a $13 \%$ reduction in the relative risk of remaining depressed and a 9-percentage point absolute reduction in the proportion of patients with persistent depression. Moreover, a review of evidence on screening for suicide risk [88], suggests that focusing on screening high-risk groups (depressed patients, substance abusers) in primary care settings may decrease suicide rates. Since depression is common, affecting about 121 million people worldwide [89], and the burden of this disease is significant -depression is the second cause of Disability Adjusted Life Years in the age category 1544 years for both sexes combined and it is expected that by the year 2020, depression will reach that status for all age groupsthere may be room to consider depression screening in primary care settings, much like screening for hypertension or diabetes.

\section{Treatment}

Suicide is complex involving psychological, social, biological, cultural and environmental elements. Therefore, a combination 
of treatment and support strategies - psychotherapy, pharmacotherapy, follow up treatment and support for those who lost a loved one to suicide, may provide effective measures against suicidal behavior.

\section{Psychotherapy}

Several evidence based psychotherapies have been shown to be of utility in the treatment of those at risk for suicidal behavior. This is the case not only because psychotherapy, with or without medication, can reduce depressive symptoms, but because it can specifically target suicidal ideation and suicide attempts [10]. For example, Cognitive Behavioral Therapy (CBT) is an evidence-based method for reducing suicide attempt rates and improving adherence to treatment. This treatment has been shown to be effective when directly focused on reducing aspects of suicidal behavior [90-93]. Similarly, given that suicidal people often lack psychosocial resources, increasing problem-solving capacity through Problem Solving Therapy may reduce the burden of unsolved problems, and as a result, reduce hopelessness, depressive symptoms and suicidal thoughts [94, 95]. Interpersonal therapy, which identifies and resolves interpersonal difficulties which cause or exacerbate psychological distress has also been found to decrease suicidal ideation [94]. As well, Dialectical Behavioral Therapy (DBT) has been shown to reduce self-injury and suicidal behavior in individuals with borderline personality disorder $[95,96]$.

\section{Pharmacotherapy}

Given the importance of psychiatric illness as a contributor to suicide risk, providing suitable, robust pharmacotherapy for psychiatric disorders is critical to suicide prevention.

\section{Antidepressants}

Depression is the psychiatric condition most often associated with suicidal behavior. The lifetime suicide risk rate among depressed (unipolar and bipolar) patients is 10-15\% [74]. Antidepressants are the treatment of choice for the relief of depressive symptoms and suicidal ideation, which often accompanies depression [97, 98]. Antidepressants significantly reduce the risk of suicidal ideation and suicidal behavior in patients with major depression [3]. Moreover, higher prescription rates of antidepressants correlate with a decrease in suicide rates [99-101]. Due to their relative safety in cases of overdose, and relatively mild side effects, SSRIs are considered first line therapy in primary care settings [102]. However, children, adolescents and young adults under the age of 24 may paradoxically experience an induction or worsening of suicidal ideation or behavior. A systematic review of randomized control trials aimed at establishing the association between SSRIs and suicide attempts [103] found a more than twofold increase in the rate of suicide attempts in patients receiving SSRIs compared with placebo or therapeutic interventions other than tricyclic antidepressants (TCA). However, there was no difference in suicide deaths between SSRIs and placebo. Similarly, a meta-analysis by Gunnel at al. [104] found weak evidence for increased risk of non-fatal self harm in patients taking SSRI's compared with placebo, but no evidence for increased suicide risk. Possible explanations for these findings are that SSRIs can cause agitation, anxiety, insomnia and akathisia at the initiation of treatment, all of which may increase suicide risk among young depressed patients. Potential solutions include closer observation of patients with mild illness who are being treated in the community by general practitioners, family and close friends.

Why younger individuals are at risk for worsening suicidal ideation upon exposure to antidepressants is not known but may be due to the complex nature of depression among children and adolescents, which can mask a bipolar disorder or personality traits. The Food and Drug Administration (FDA) has issued a "black box" warning on the use of antidepressants among this age group [105], and it is recommended that children and adolescents taking this class of medication be under close monitoring for side effects. Clearly, the clinician must consider the risks and benefits entailed in the use of antidepressants, especially SSRIs, in the treatment of depression in patients under the age of 24 .

\section{Mood Stabilizers}

Lithium is reported to reduce both attempted and completed suicides in major mood disorders, such as unipolar depression and bipolar patients with long-term lithium treatment $[106,107]$. A meta analysis by Baldessarini et al. [106] found that risk of completed and attempted suicide were lower by approximately $80 \%$, during treatment of bipolar and other major affective disorder patients with lithium. Long term lithium treatment also may reduce the lethality of suicidal acts, perhaps by limiting impulsivity and aggressiveness. Nonetheless, a cause for concern is lithium's limited therapeutic index or margin of safety, such that lethal outcomes can occur in the setting of suicide attempt by overdose. Interestingly, the fatality risk of lithium overdoses is moderate, much like that of modern antidepressants and second-generation antipsychotics [108]. That notwithstanding, close patient monitoring and education about adherence to treatment is important since abrupt discontinuation of the treatment with mood stabilizers can cause a rebound increase in suicidal ideation $[109,110]$.

\section{Antipsychotics}

Clozapine has been shown to have an anti-suicidal effect in schizophrenia [111] compared to both placebo and other 
second generation antipsychotics and is the only FDA approved drug for treatment of suicidal behavior. Of note, a study by Spivac et al. [112] suggests that this effect is due, in part, to a reduction in impulsiveness and aggression. However, because suicidal ideation and behavior in schizophrenia can emerge as part of an acute psychosis, severe anxiety, agitation, or depression, sedating antipsychotics or antidepressants respectively, may be useful. Given that some atypical antipsychotics have antidepressant effects $[113,114]$ they may also be of utility in schizophrenia accompanied by suicide risk.

\section{Electroconvulsive Therapy}

There is extensive evidence that ECT is an effective treatment for acute suicidality among severely depressed patients [115]. This treatment can also reduce the risk of subsequent suicidal behavior. Thus, although in most countries the use of Electroconvulsive therapy (ECT) is reserved for major depressive episodes that have been shown to be "treatment resistant" to adequate trials of two or more pharmacotherapies, presence of acute suicide risk should clearly be an indication for ECT regardless of the treatment history.

\section{Follow-Up After Suicide Attempt}

Recurrent suicidal behavior places a great burden on patients and their families, as well as on the health care system as a whole. Since previous suicide attempts are a major risk factor in predicting further suicidal behavior and suicide [116, 117], adequate follow-up care after a suicide attempt for patients and their families is crucial in prevention. A few methods have been found to be efficient. The Green Card Study [118] is an initiative aimed at increasing compliance among Deliberate Self Harm patients after discharge. The initiative offered patients after deliberate self harm a "lifeline"- easy access to on call psychiatrists, and encouraged them to make contact should difficulties arise. A doctor was available at all times, and the intervention included crisis admission if necessary. This kind of initiative showed a significant reduction of deliberate self-harm. Furthermore, it did not require a significant amount of resources. Carter et al. [119] found that ongoing contact after hospital discharge via postcards lowered the number of repeat suicide attempts by nearly $50 \%$. This model emphasized social connectedness, respect for the patient and high quality medical and psychiatric management after hospital discharge. The Norwegian initiative [120] which provided follow-up care after suicide attempts via a chain-of-care network also is reported to reduce suicide rates. Involvement of the family in aftercare following a suicide attempt is critical since they may constitute the main support system. The family may also serve as after care monitors for treatment adherence and detection of any signs of suicidality [121].

\section{Conclusions}

Suicide prevention requires strategies that encompass work at the individual, systems and community level. Policy directed at means restriction and public awareness campaigns can be used in combination with strategies directed at the individual, including identification, proper diagnosis and effective treatments. Given the complexity of identifying and managing suicide risk, a combination of interventions at several levels will be required in order to implement an efficacious, comprehensive prevention program.

Acknowledgments Research on this paper was supported by MH 48514 and the Conte Center for the Neurobiology of Suicidal Behavior MH 62185.

Disclosure M. Schwartz-Lifshitz: none; G. Zalsman: none; L. Giner has received compensation for development of educational presentations from Servier, Bristol-Myers Squibb, Janssen, and GlaxoSmithKline; has received compensation for travel, accommodations, and meeting expenses from Servier, Bristol-Myers Squibb, Janssen, and GlaxoSmithKline; and has received compensation for development of a presentation from GlaxoSmithKline; M.A. Oquendo receives royalties for the use of the Columbia Suicide Severity Rating Scale; has received financial compensation from Pfizer for the safety evaluation of a clinical facility, unrelated to the current manuscript; was the recipient of a grant from Eli Lilly to support a year's salary for the Lilly Suicide Scholar, Enrique Baca-Garcia, $\mathrm{MD}, \mathrm{PhD}$; and has received unrestricted educational grants and/or lecture fees from AstraZeneca, Bristol-Myers Squibb, Eli Lilly, Janssen, Otsuko, Pfizer, Sanofi-Aventis, and Shire. Her family owns stock in Bristol-Myers Squibb.

\section{References}

Papers of particular interest, published recently, have been highlighted as:

- Of importance

•- Of major importance

1. http://www.who.int/topics/suicide/en/

2. WHO mortality database. http:/www.who.int/healthinfo/morttables/en/.

3. Wasserman D, Rihmer Z, Rujescu D, Sarchiapone M, Sokolowski M, Titelman D, Zalsman G, Zemishlany Z, Carli V. European psychiatric association Guidance on Suicide treatment and Prevention. Eur Psychiatry. 2012;27(2):129-41.

4. Posner K, Oquendo MA, Gould M, Stanley B, Davies M. Columbia Classification Algorithm of Suicide Assessment (C-CASA): classification of suicidal events in the FDA's pediatric suicidal risk analysis of antidepressants. Am J Psychiatry. 2007;164(7):1035-43.

5. Pompili M, Rihmer Z, Innamorati M, Lester D, Girardi P, Tatarelli $\mathrm{R}$. Assessment and treatment of suicide risk in bipolar disorders. Expert Rev Neurother. 2009;9(1):109-36.

6. Soloff PH, Fabio A. Prospective predictors of suicide attempts in borderline personality disorder. J Pers Disord. 2008;22(2):123-34.

7. Soloff PH, Fabio A, Lonnqvist J. Major psychiatric disorders in suicide and suicide attempters. In: Wasserman D, Wasserman C, editors. Oxford textbook of suicidology and suicide prevention: a global perspective. Oxford: Oxford University Press; 2009. p. 275-86. 
8. Rihmer Z. Suicide risk in mood disorders. Curr Opin Psychiatry. 2007;20:17-22.

9. Mann JJ, Ellis SP, Waternaux CM, Liu X, Oquendo MA, Malone KM, Brodsky BS, Haas GL, Currier D. Classification trees distinguish suicide attempters in major psychiatric disorders: a model of clinical decision making. J Clin Psychiatry. 2008;69(1):23-31.

10. Mann JJ, Apter A, Bertolote J, Beautrais A, Currier D, Haas A, Hegerl U, Lonnqvist J, Malone K, Marusic A, Mehlum L, Patton G, Phillips M, Rutz W, Rihmer Z, Schmidtke A, Shaffer D, Silverman M, Takahashi Y, Varnik A, Wasserman D, Yip P, Hendin H. Suicide prevention strategies: a systematic review. JAMA. 2005;294:2064-74.

11. Luoma JB, Martin CE, Pearson JL. Contact with mental health and primary care providers before suicide: a review of the evidence. Am J Psychiatry. 2002;159:909-16.

12. Andersen UA, Andersen M, Rosholm JU, Gram LF. Contacts to the health care system prior to suicide: a comprehensive analysis using registers for general and psychiatric hospital admissions, contacts to general practitioners and practicing specialists and drug prescriptions. Acta Psychiatr Scand. 2000;102:126-34.

13. Lopez AD, Mathers CD, Ezzati M, Jamison DT, Murray CJ. Global and regional burden of disease and risk factors: systematic analysis of population health data. Lancet. 2006;367:1747-57.

14. Isacsson G, Holmgren P, Druid H, Bergman U. The utilization of antidepressants-a key issue in the prevention of suicide: an analysis of 5281 suicides in Sweden during the period 1992-1994. Acta Psychiatr Scand. 1997;96:94-100.

15. Isacsson G, Holmgren P, Wasserman D, Bergman U. Use of antidepressants among people committing suicide in Sweden. BMJ. 1994:308:506-9.

16. Oquendo MA, Currier D, Mann JJ. Prospective studies of suicidal behavior in major depressive and bipolar disorders: what is the evidence for predictive risk factors? Acta Psychiatr Scand. 2006;114:151-8.

17. - Lonnqvist J. Major Psychiatric disorders in suicide and suicide attempts. In: Wasserman D, Wasserman C, editors. Oxford textbook of suicidology and suicide prevention: a global perspective. Oxford: Oxford University Press; 2009. p. 275-86. This systematic review of disorders that serve as risk factors for both suicide and suicide attempts provides a comprehensive summary of the literature to date.

18. Boden JM, Fergusson DM, Horwood LJ. Anxiety disorders and suicidal behaviours in adolescence and young adulthood: findings from a longitudinal study. Psychol Med. 2007;37:431-40.

19. Fawcet J, Scheftner WA, Fogg L, Clark DC, Young MA, Hedeker $\mathrm{D}$, Gibbons R. Time relared predictors of suicide in major affective disorders. Am J Psychiatry. 1990;147:1189-94.

20. Johnson J, Weissman M, Klerman GL. Panic disorder, comorbidity, and suicide attempts. Arch Gen Psychiatry. 1990;47:805-8.

21. Placidi PG. Anxiety in major depression: relationship to suicide attempts. Am J Psychiatry. 2000;157(10):1614-8.

22. Panagioti M, Gooding P, Tarrier N. Post-traumatic stress disorder and suicidal behavior: a narrative review. Clin Psychol Rev. 2009;29:471-82.

23. Pirkola SP, Isometsa ET, Heikkinen ME, Lonnqvist JK. Suicides of alcohol misusers and non-misusers in a nationwide population. Alcohol Alcohol. 2000;35:70-5.

24. Oquendo MA, Currier D, Liu S, Hasin D, Grant B, Blanco C. Increased risk for suicidal behavior in comorbid bipolar disorder and alcohol use disorders. J Clin Psychiatry. 2010;71(7):902-9.

25. Bushe C, Taylor M, Haukka J. Mortality in schizophrenia - A measurable clinical endpoint. J Psychopharmacol. 2010;24 (4):17-25.

26. Palmer BA, Pankratz VS, Bostwick JM. The lifetime risk of suicide in schizophrenia: a reexamination. Arch Gen Psychiatry. $2005 ; 62: 247-53$.
27. Haw C, Hawten K, Sutton L, Sinclair J, Deeks J. Schizophrenia and deliberate self harm: a systematic review of risk factors. Suicide Life Threat Behav. 2005;35:50-62.

28. Hor K, Taylor M. Suicide and schizophrenia: a systematic review of rates and risk factors. J Psychopharmacol. 2010;24(4):81-90.

29. Stanely B, Jones J. Risk for suicidal behavior in personality disorders. In: Wasserman D, Wasserman C, editors. Oxford textbook of suicidology and suicide prevention: a global perspective. Oxford: Oxford University Press; 2009. p. 287-92.

30. Chioqueta AP, Stiles TC. Assessing suicide risk in cluster C personality disorders. Crisis. 2004;25:128-33.

31. Schneider B, Watterling T, Sargk D, Schneider F, Schnabel A, Maurer K, Fritze J. Axis one disorders and personality disorders as risk factors for suicide. Eur Arch Psychiatry Clin Neurosci. 2006;256:17-27.

32. Sabo AN, Gunderson JG, Najavits LM, Chauncey D, Kisiel C. Changes in self-destructiveness of borderline patients in psychotherapy. A prospective follow-up. J Nerv Ment Dis. 1995;183:370-6.

33. Malone KM, Haas GL, Sweeney JA, Mann JJ. Major depression and the risk of attempted suicide. J Affect Disord. 1995;34 (3):173-185.

34. Oquendo MA, Waternaux C, Brodsky B, Parsons B, Haas GL, Malone KM, Mann JJ. Suicidal behavior in bipolar mood disorder: clinical characteristics of attempters and nonattempters. J Affect Disord. 2000;59:107-17.

35. Maser JD, Akiskal HS, Schettler P, Scheftner W, Mueller T, Endicott J, Solomon D, Clayton P. Can temperament identify affectively ill patients who engage in lethal or near-lethal suicidal behavior? a 14-year prospective study. Suicide Life Threat Behav. 2002;32:10-32.

36. Schneider B, Philipp M, Muller MJ. Psychopathological predictors of suicide in patients with major depression during a 5-year follow-up. Eur Psychiatry. 2001;16:283-8.

37. Keller F, Wolfersdorf M. Hopelessness and the tendency to commit suicide in the course of depressive disorders. Crisis. 1993;14:173-7.

38. Sidley GL, Calam R, Wells A, Hughes T, Whitaker K. The prediction of parasuicide repetition in a high-risk group. Br J Clin Psychol. 1999;38:375-86.

39. Brent DA, Mann JJ. Family genetic studies, suicide, and suicidal behavior. Am J Med Genet C Semin Med Genet. 2005;133C:13-24.

40. Roy A, Janal M. Family history of suicide, female sex, and childhood trauma: separate or interacting risk factors for attempts at suicide? Acta Psychiatr Scand. 2005;112:367-71.

41. Roy A, Nielson D, Rylander G, Sarchiapone M. The genetics of suicidal behavior. In: Hawton $\mathrm{K}$, van Heeringen $\mathrm{K}$, editors. The international handbook of suicide and attempted suicide. Wiley: Chichester; 2000. p. 209-22.

42. Egeland JA, Sussex JN. Suicide and family loading for affective disorders. JAMA. 1985;254(7):915-8.

43. Brent DA, Oquendo M, Birmaher B, Greenhill L, Kolko D, Stanley B, Zelazny J, Brodsky B, Bridge J, Ellis S, Salazar JO, Mann JJ. Familial pathways to early-onset suicide attempt: risk for suicidal behavior in offspring of mood-disordered suicide attempters. Arch Gen Psychiatry. 2002;59(9):801-7.

44. Brent DA. Peripubertal suicide attempts in offspring of suicide attempters with siblings concordant for suicidal behavior. Am J Psychiatry. 2003;160(8):1486-93.

45. Melhem NM. Familial pathways to early-onset suicidal behavior: familial and individual antecedents of suicidal behavior. Am J Psychiatry. 2007;164(9):1364-70.

46. Cassidy F. Risk factors of attempted suicide in bipolar disorder. Suicide Life-Threat Behav. 2011;41:6-11.

47. Goodwin FK, Fireman B, Simon GE, Hunkeler EM, Lee J, Revicki D. Suicide risk in bipolar disorder during treatment with lithium and divalproex. JAMA. 2003;290:1467-73. 
48. Harris EC, Barraclough B. Suicide as an outcome for mental disorders. A meta-analysis. Br J Psychiatry. 1997;170:205-28.

49. Hawton K, Sutton L, Haw C, Sinclair J, Harriss L. Suicide and attempted suicide in bipolar disorder: a systematic review of risk factors. J Clin Psychiatry. 2005;66:693-704.

50. Rihmer Z. Pharmacological prevention of suicide in bipolar patients - a realizable target. J Affect Disord. 2007;103:1-3.

51. Rihmer Z. Suicide risk in mood disorders. Curr Opin Psychiatry. 2007;20:17-22.

52. Rihmer Z, Kiss K. Bipolar disorders and suicidal behaviour. Bipolar disorder. 2002;4(1):21-5.

53. Leon AC, Keller MB, Warshaw MG, Mueller TI, Solomon DA, Coryell W, Endicott J. A prospective study of fluoxetine treatment and suicidal behavior in affectively ill subjects. Am J Psychiatry. 1999;156:195-201.

54. Oquendo MA, Kamali M, Ellis SP, Grunebaum MF, Malone KM, Brodsky BS, Sackeim HA, Mann JJ. Adequacy of antidepressant treatment after discharge and the occurrence of suicidal acts in major depression: a prospective study. Am J Psychiatry. 2002;159:1746-51.

55. Valtonen H, Suominen K, Mantere O, et al. Suicidal ideation and attempts in bipolar I and bipolar II disorders. J Clin Psychiatry. 2005;66:1456-62.

56. Coryell W, Young EA. Clinical predictors of suicide in primary major depressive disorder. J Clin Psychiatry. 2005; 66:412-7.

57. Hayes LM. Juvenile suicide in confinement in the United States: results from a National Survey. Crisis. 2005;26:146-8.

58. Williams JMG, Crane C, Van der Does AJW, Segal ZV. Recurrence of suicidal ideation across depressive episodes. J Affect Disord. 2005;91:189-94.

59. Galfalvy H, Oquendo MA, Carballo JJ, Sher L, Grunebaum MF, Burke A, Mann JJ. Clinical predictors of suicidal acts after major depression in bipolar disorder: a prospective study. Bipolar Disord. 2006;8:586-95.

60. Fagiolini A, Kupfer DJ, Rucci P, Scott JA, Novick DM, Frank E. Suicide attempts and ideation in patients with bipolar I disorder. J Clin Psychiatry. 2004;65:509-14.

61. Hegerl U, Wittmann M, Arensman E, Van Audenhove C, Bouleau JH, Van Der Feltz-Cornelis C, Gusmao R, Kopp M, Lohr C, Maxwell M. The 'European Alliance Against Depression (EAAD)': a multifaceted, community-based action programme against depression and suicidality. World J Biol Psychiatry. 2008;9:51-8

62. U.S. Suicide Statistics (2005) http://www.suicide.org/suicide-statistics

63. Beautrais A, Fergusson D, Coggan C, Collings C, Doughty C, Ellis P, Hatcher S, Horwood J, Merry S, Mulder R, Poulton R, Surgenor L. Effective strategies for suicide prevention in New Zealand:a review of the evidence. The new Zealand journal of medicine 2007;120.

64. Bridges FS, Kunselman JC. Gun availability and use of guns for suicide, homicide, and murder in Canada. Percept Mot Skills. 2004;98:594-8.

65. Miller M, Azrael D, Hepburn L, Hemenway D, Lippmann SJ. The association between changes in household firearm ownership and rates of suicide in the United States, 1981-2002. Inj Prev. 2006; 12:178-82.

66. Kapusta ND, Etzersdorfer E, Krall C, Sonneck G. Firearm legislation reform in the European Union: impact on firearm availability, firearm suicide and homicide rates in Austria. Br J Psychiatry. 2007:191:253-7.

67. Shelef M. Unanticipated benefits of automotive emission control: reduction in fatalities by motor vehicle exhaust gas. Sci Total Environ. 1994;146-147:93-101.

68. Kelly S, Bunting J. Trends in suicide in England and Wales, 1982-96. Popul Trends. 1998;92:29-41.
69. Bennewith O, Nowers M, Gunnell D. Suicidal behaviour and suicide from the Clifton Suspension Bridge, Bristol and surrounding area in the UK: 1994-2003. Eur J Public Health. 2011;21:204-8.

70. Lin JJ, Lu TH. Association between the accessibility to lethal methods and method-specific suicide rates: an ecological study in Taiwan. J Clin Psychiatry. 2006;67:1074-9.

71. Gunnell D, Bennewith O, Hawton K, Simkin S, Kapur N. The epidemiology and prevention of suicide by hanging: a systematic review. Int J Epidemiol. 2005;34:433-42.

72. Sarchiapone M, Mandelli L, Iosue M, Andrisano C, Roy A. Controlling access to suicide means. Int $\mathrm{J}$ Environ Res Public Health. 2011;8:4550-62.

73. Tsai CW, Gunnell D, Chou YH, Kuo CJ, Lee MB, Chen YY. Why do people choose charcoal burning as a method of suicide? An interview based study of survivors in Taiwan. J Affect Disord. 2011;131:402-7.

74. Sonneck G, Etzersdorfer E, Nagel-Kuess S. Imitative suicide on the Viennese subway. Soc Sci Med. 1994;38:453-7.

75. ••van der Feltz-Cornelis CM, Sarchiapone M, Postuvan V, Volker D, Roskar S, Grum AT, Carli V, McDaid D, O'Connor R, Maxwell M, Ibelshäuser A, Van Audenhove C, Scheerder G, Sisask M, Gusmão R, Hegerl U. Best practice elements of multilevel suicide prevention strategies: a review of systematic reviews. Crisis. 2011;32(6):319-33. This concise meta-review summarizes the data relevant to designing a comprehensive suicide prevention model, addressing the various levels of intervention that are essential to an effective campaign.

76. Knox KL, Litts DA, Talcott WJ, Catalano Feig J, Caine ED. Risk of suicide and related adverse outcomes after exposure to a suicide prevention programme in the US Air Force: cohort study. BMJ. 2003;327:1376-8.

77. Hegerl U, Althaus D, Stefanek J. Public attitudes towards treatment of depression: effects of an information campaign. Pharmacopsychiatry. 2003;36:288-91.

78. Jorm AF, Christensen H, Griffiths KM. The impact of beyondblue: the national depression initiative on the Australian public's recognition of depression and beliefs about treatments. Aust NZJ Psychiatry. 2005;39:248-54.

79. Akroyd S, Wyllie J. Impacts of National Media Campaign to Counter Stigma and Discrimination Associated with Mental Illness: Survey 4 . Wellington, New Zealand: New Zealand Ministry of Health; 2002. Publication 9-20-0004.

80. - Dumesnil H, Verger P. Public awareness campaigns about depression and suicide: a review. Psychiatr Serv. 2009;60:1203-13. The role of policy in public health and suicide prevention in particular is highlighted in this review of the evidence.

81. Hegerl U, Althaus D, Schmidtke A, Niklewski G. The alliance against depression: 2-year evaluation of a community-based intervention to reduce suicidality. Psychol Med. 2006;36:1225-33.

82. Leitner M, Barr W, Hobby L. Effectiveness of interventions to prevent suicide and suicidal behavior: a systematic review. Edinburgh, UK: Scottish Government Social Research; 2008.

83. Szanto K, Kalmar S, Hendin H, Rihmer Z, Mann JJ. A suicide prevention program in a region with a very high suicide rate. Arch Gen Psychiatry. 2007;64:914-20.

84. Mehlum L, Schwebs R. Suicide prevention in the military: recent experiences in the Norwegian army. In: Program and abstracts of the 33rd International Congress on Military Medicine; June 25-30, 2000; Helsinki, Finland.

85. Wyman PA, Brown CH, Inman J, Cross W, Schmeelk-Cone K, Guo J, Pena JB. Randomized trial of a gatekeeper program for suicide prevention: 1-year impact on secondary school staff 2008 . J Consult Clin Psychol. 2008;76(1):104-15.

86. Shaffer D, Scott M, Wilcox H, Maslow C, Hicks R, Lucas CP, Garfinkel R, Greenwald S. The Columbia Suicide Screen: validity 
and reliability of a screen for youth suicide and depression. J Am Acad Child Adolesc Psychiatry. 2004;43:71-9.

87. Pignone MP, Gaynes BN, Rushton JL, Burchell CM, Orleans CT, Mulrow CD, Lohr KN. Screening for depression in adults: a summary of the evidence for the US Preventive Services Task Force. Ann Intern Med. 2002;136:765-76.

88. Gaynes BN, West SL, Ford CA, Frame P, Klein J, Lohr KN. Screening for suicide risk in adults: a summary of the evidence for the US Preventive Services Task Force. Ann Intern Med. 2004; 140:822-35.

89. http://www.who.int/mental_health/management/depression/ definition/en

90. Stanley B, Brown G, Brent DA, et al. Cognitive-behavioral therapy for suicide prevention (CBT-SP): treatment model, feasibility, and acceptability. J Am Acad Child Adolesc Psychiatry. 2009;48:1005-13.

91. Rudd MD, Williams B, Trotter D. The psychological and behavioural treatment of suicidal behaviour: what are the common elements of treatment that work? In: Wasserman D, Wasserman C, editors. Oxford textbook of suicidology and suicide prevention: a global perspective. Oxford: Oxford University Press; 2009. p. 427-37.

92. Tarrier N, Taylor K, Gooding P. Cognitive-behavioral interventions to reduce suicide behavior a systematic review and meta-analysis. Behav Modif. 2008;32:77-108.

93. Brown GK, Ten Have TR, Henriques GR, Xie SX, Hollander JE, Beck AT. Cognitive therapy for the prevention of suicide attempts: a randomized controlled trial. JAMA. 2005;294:563-70.

94. Cognitive treatment of suicidal adults In: Wasserman D, Wasserman C, editors. Oxford Textbook of Suicidology and Suicide Prevention: a Global Perspective. Oxford: Oxford University Press; 2009. p. 413-420.

95. DBT for suicidal individuals in: Wasserman D, Wasserman C, editors. Oxford Textbook of Suicidology and Suicide Prevention: a Global Perspective. Oxford: Oxford University Press; 2009. p. 421-425.

96. Linehan MM, Comtois KA, Murray AM, Brown MZ, Gallop RJ, Heard HL, Korslund KE, Tutek DA, Reynolds SK, Lindenboim N. Two-year randomized controlled trial and follow-up of dialectical behavior therapy vs therapy by experts for suicidal behaviors and borderline personality disorder. Arch Gen Psychiatry. 2006;63:757.

97. Bauer M, Bschor T, Pfenning A, Whybrow PC, Angst J, Versiani M, Möller HJ. World Federation of Societies of Biological Psychiatry (WFSBP) guiedelines for Biological Treatment of Unipolar Depressive Disorders in primary care. World J Biol Psychiatry. 2007;8:67-104.

98. Bauer M, Whybrow PC, Angst J, Versiani M, Möller HJ. World Federation Of Societies Of Biological Psychiatry (WFSBP) guiedelines for Biological Treatment of Unipolar Depressive Disorders, part 1: acute and continuation treatment of major depressive disorder. World J Biol Psychiatry. 2002;3:5-43.

99. Gibbons RD, Hur K, Bhaumik DK, Mann JJ. The relationship between antidepressant medication use and rate of suicide. Arch Gen Psychiatry. 2005;65:165-72.

100. Olfson M, Shaffer D, Marcus SC, Greenberg T. Relationship between antidepressant medication treatment and suicide in adolescents. Arch Gen Psychiatry. 2003;60:978-82.

101. Hall WD, Mant A, Mitchell PB, Rendle VA, Hickie IB, McManus $\mathrm{P}$. Association between antidepressant prescribing and suicide in Australia, 1991-2000: trend analysis. BMJ. 2003;326:1008.

102. Moller HJ. Pharmacological and other biological treatments of suicidal individuals. In: Wasserman D, Wasserman C, editors. Oxford textbook of suicidology and suicide prevention: a global perspective. Oxford: Oxford University Press; 2009. p. 395-405.

103. Fergusson D, Doucette S, Glass KC, Shapiro S, Healy D, Hebert P, Hutton B. Association between suicide attempts and selective serotonin reuptake inhibitors: systematic review of randomised controlled trials. BMJ. 2005;330:396.

104. Gunnell D, Saperia J, Ashby D. Selective Serotonin Reuptake Inhibitors (SSRIs) and suicide in adults: meta-analysis of drug company data from placebo controlled, randomized controlled trials submitted to the MHRA's safety review. BMJ;330:385

105. http://www.fda.gov/Drugs/DrugSafety/InformationbyDrugClass/ ucm096273.ht

106. Baldessarini RJ, Tondo L, Davis P, Pompili M, Goodwin FK, Hennen J. Decreased risk of suicides and attempts during longterm lithium treatment: a meta-analytic review. Bipolar Disord. 2006;8:625-39.

107. Guzzetta F, Tondo L, Centorrino F, Baldessarini RJ. Lithium treatment reduces suicide risk in recurrent major depressive disorder. J Clin Psychiatry. 2007;68:380-3.

108. Watson WA, Litovitz TL, Klein-Schwartz W, Rodgers Jr GC, Youniss J, Reid N, Rouse WG, Rembert RS, Borys D. 2003 Annual report of the American association of poison control centers toxic exposure surveillance system (TESS). Am J Emerg Med. 2004;22:335-404.

109. Tondo L, Isacsson G, Baldessarini R. Suicidal behavior in bipolar disorder: risk and prevention. CNS Drugs. 2003;17(7):491-511.

110. Yerevanian B, Koek R, Mintz J. Bipolar pharmacotherapy and suicidal behavior. Part I: Lithium, divalproex and carbamazepine. J Affect Disord. 2007;103:5-11.

111. Meltzer HY, Baldessarini RJ. Reducing the risk for suicide in schizophrenia and affective disorders. J Clin Psychiatry. 2003;64:1122-9.

112. Spivac B, Shabash E, Sheitman B, Weizman A, Mester R. The effects of clozapine versus haloperidol on measures of impulsive aggression and suicidality in chronic schizophrenia patients: an open, non-randomized, 6-month study. J Clin Psychiatry. 2003;64:755-60.

113. Moller HJ. Antipsychotic and antidepressive effects of second generation antipsychotics Two different pharmacological mechanisms? Eur Arch Psychiatry Clin Neurosci. 2005;255:190-201.

114. Moller HJ. Antidepressive effects of traditional and second generation antipsychotics: a review of the clinical data. Eur Arch Psychiatry Clin Neurosci. 2005;255:83-93.

115. Kennedy SH, Milev R, Giacobbe P, Ramasubbu R, Lam RW, Parikh SV, Patten SB, Ravindran AV. Canadian Network for Mood and Anxiety Treatments (CANMAT) Clinical guidelines for the management of major depressive disorder in adults. IV. Neurostimulation therapies. J Affect Disord. 2009;117(1): S44-53.

116. Beautrais AL. Subsequent mortality in medically serious suicide attempts: a 5 year follow-up. Aust New Zeal J Psychiatry. 2003;37:595-9.

117. Suicide attempts in Europe in: Wasserman D, Wasserman C, editors. Oxford Textbook of Suicidology and Suicide Prevention: a Global Perspective. Oxford: Oxford University Press; 2009. p. $123-126$

118. Morgan HG, Jones EM, Owen JH. Secondary prevention of Nonfatal deliberate self-harm the green card study. Br J Psychiatry. 1993;163:111-2.

119. Carter GL, Clover K, Whyte IM, Dawson AH, D'Este C. Postcards from the EDge project: randomised controlled trial of an intervention using postcards to reduce repetition of hospital treated deliberate self poisoning. BMJ. 2005;331:805.

120. Dieserud G, Loeb M, Ekeberg O. Suicidal behavior in the municipality of Baerum, Norway: a 12-year prospective study of parasuicide and suicide. Suicide Life Threat Behav. 2000;30:61-73.

121. Family psychoeducation with suicide attempters. In: Wasserman D, Wasserman C, editors. Oxford textbook of suicidology and suicide prevention: a global perspective. Oxford: Oxford University Press; 2009; p. 439-443. 